\title{
Vertical Handoff Decision Strategies in Heterogeneous Wireless Networks
}

\author{
Jyoti Madaan \\ MRIU, Faridabad, India \\ Department of Electronics \& Comm. Engineering
}

\author{
Indu Kashyap \\ MRIU, Faridabad, India \\ Department of Computer Science \&Engineering
}

\begin{abstract}
In wireless communications of fourth generation the expectation to assimilate a hypothetically numerous heterogeneous wireless technologies are happened under consideration of a novel step toward worldwide smooth access. The advancement in wireless networks increases the challenges of mobility management as well the challenges of merging a various number of wireless networks. Out of those the main challenge for smooth movement is the accessibility of consistent vertical (intersystem) and horizontal (intrasystem) handoff processes. So to improve the quality of service and to provide continuous connectivity these handoff schemes must be efficient.

This paper represents various features of handoff and discusses various factors related to handoff. Hand-off management process, Hand-off types, Handoff decisions problems and Vertical Handoff decision strategies and a brief comparative review of different handoff VHD strategies is presented through tabular form.
\end{abstract}

\section{Keywords}

Vertical Handoff Decision (VHD), Vertical Handoff Process (VHO), Horizontal Handoff Process (HHO).

\section{INTRODUCTION}

In cell mobile systems, the scope area are divided into smaller cells, to achieve high system capacity. Each cell has its own base station (BS), which provides the services to the mobile node. It allocates a group of channels or frequencies to a mobile node before a communication take place between different users. The mobile node is allowed to move freely from one cell to another. The handoff process is triggered, when a mobile node crosses a boundary of the cell and observes a delay in the received signal strength.

This paper is organized into eleven sections including introduction. Section-I \& II gives an introduction for heterogeneous wireless networks and types of Handoff. In section III Handoff management problem is discussed in depth. Section IV to VIII gives a detailed description of handoff features, requirement, reasons of handoff failure, resource management,vertical handoff problem, criteria \& performance evaluation metrics for VHD algorithm. SectionIX \& X covers various Handoff strategies along their pros \& cons. Section-XI contains the conclusion of the study of various Handoff strategies. We have divided the vertical handoff systems into four sorts of techniques, for example, RSS based methods, Bandwidth based, Cost function based and Combination algorithm.

\section{TYPES OF HANDOFF}

On a fundamental level, every mobile node is served by at least one base station. The measurements and profile of each cell rely upon the network type, number of frequencies used and number of base station [1]. Therefore, Handoff can be classified in six categories depending upon these factors as shown in figure 1.

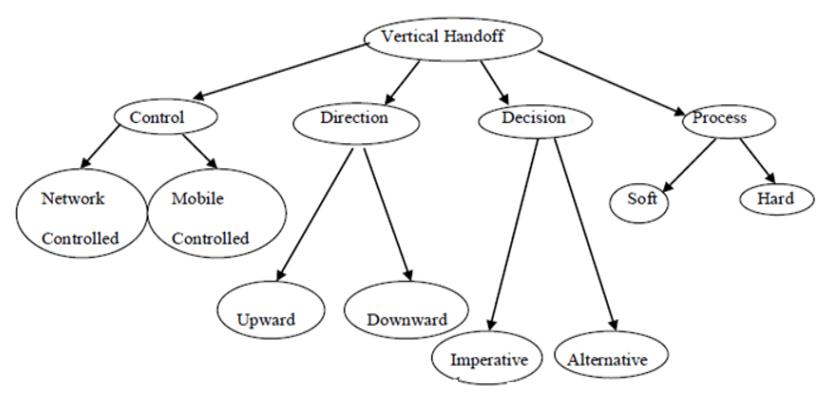

Fig. 1. Types of Handoff

\subsection{First Factor: Network Types Involved}

Handoffs can be categorized as either vertical or horizontal handoff depending upon type of network interfaces involved.

\subsubsection{Horizontal handoff:}

In this handoff procedure, the node switches between same network technologies. For instance, the switching between signal transmissions from a topographically neighboring IEEE $802.11 \mathrm{~b}$ base station to an IEEE $802.11 \mathrm{~b}$ base station is considered as a horizontal handoff process.

\subsubsection{Vertical handoff:}

In this, handoff methodology the mobile node switches among different network technology. For instance, the switching between signal transmissions from an overlaid cell network to an IEEE $802.11 \mathrm{~b}$ base station is viewed as a vertical handoff process.

\subsection{Second Factor: Frequencies Engaged}

\subsubsection{Intra-frequency handoff:}

In this handoff process, the mobile node switches between networks working on the same frequency. This sort of handsoff is exhibited in code-division multiple access (CDMA) networks with frequency-division duplex (FDD).

\subsubsection{Inter-frequency handoff:}

In this handoff procedure, the mobile node switches among networks operating on different frequencies. This sort of hand-off is used in in CDMA with time-division duplex (TDD). 


\subsection{Third Factor: Number Of Connections Involved}

Handoffs can be classified as hard, soft, or softer.

\subsubsection{Hard handoff:}

In a hard handoff the radio link to the old base station is terminated in the meantime a radio connection to the new base station is established.

\subsubsection{Soft handoff:}

In a soft handoff a mobile node maintains an old connection while its association with the new base station.

\subsubsection{Softer handoff:}

Fundamentally, both soft and softer handoffs are the same, with the exception that mobile node switches connection over radio links that belong to the same access point

\subsection{Fourth Factor: Administrative Domains Involved}

A managerial area is a gathering of frameworks and systems worked with a solitary association of regulatory power.

\subsubsection{Intra-administrative handoff:}

A handoff process where the mobile node oversaw by the same authoritative space and exchanges between distinctive systems.

\subsubsection{Inter-administrative handoff:}

A handoff process where the mobile node oversaw by distinctive managerial spaces and exchanges between distinctive systems.

\subsection{Fifth Factor: Necessity Of Handoff}

Handoffs can be classified based on need.

\subsubsection{Obligatory handoff:}

This type of handoff is required in situations, when it is vital for the mobile node to exchange the connection to avoid the disconnection.

\subsubsection{Voluntary handoff:}

In voluntary handoff, exchange of association is nonobligatory and could possibly enhance the quality of service.

\subsection{Sixth Factor: User Control Allowance}

Handoffs can be classified as proactive or passive.

\subsubsection{Proactive handoff:}

In a proactive handoff, the mobile is permitted to choose when to handoff. It means mobile node has control over the handoff process.

\subsubsection{Passive handoff:}

In this, network is permitted to control the handoff process. This kind of handoff is the most widely recognized in first, second, and third generation wireless systems.

\section{HANDOFF MANAGEMENT PROCESS}

Figure 2 shows, different vertical handover management process. Vertical handover decision procedure decides the need of handoff, the privilege system and the privilege time for handoff to happen \& minimize the overall signal overloading, keeping away from unnecessary handoffs and taking care of client requests are the aim of vertical handover decision plans.

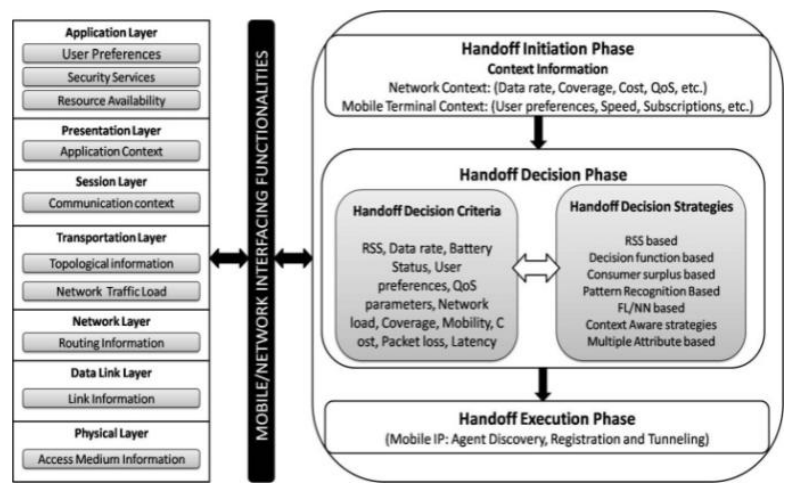

Fig. 2. Handoff management Process in collaboration with network layers

The decision criterion function of vertical handoff incorporates the abilities of mobile terminals, client requests, system conditions and application prerequisites. Expanding interest for the integration of different wireless technologies and web, alongside snappy outgrowth in the number and the sort of managements for mobile subscribers has brought about mobility management, a challenge for $4 \mathrm{G}$ frameworks.

Mobility management is the combination of location management and handoff management. Location management manages the location of the mobile node and permits the mobile node to move anywhere in heterogeneous network [2]. Handoff administration is the process by which a mobile node keeps its connectivity alive while going from the controlled domain of one base station into the managed domain of an alternate base station. Fig. 2 dlineates handoff administration process.

The whole vertical handoff management methodology can be fractioned into three steps, for example, handoff initiation, handoff decision and handoff execution [3]. The point of handoff initiation stage is to recognize the need of handoff and introducing it if needed. At this stage, selective information of parameters, for example, RSS, transfer speed, connection rate, system load, throughput, jitter, expense, power utilization, client inclination and system memberships will be collected. Different instances activated at different layers can be utilized as channels for gathering the data. The best system for handoff and the privilege time for handoff these two questions basically drive the usefulness of the handoff decision stage. In handoff execution stage, handoff procedure will be executed. In this stage, mobile terminal connection and the profile of the client will be exchanged to the new system. Efforts to establish safety, such as, verification and approval will likewise be executed in this stage [4].

\section{REASONS FOR HANDOFF FAILURE}

In the event that contiguous cells don't have enough channels to support the handoff, the call is compelled to be dropped. An imperative issue to point of confinement the likelihood of constrained call end, since from the client perspective end of a continuous call is less alluring than obstructing another call. Therefore, the framework must reserve few channels for handoff calls to diminish the possibilities of unsuccessful handoffs [5]. 


\section{RESOURCE MANAGEMENT}

Assets in wireless systems are frequency channels, the quantity of receivers, time slots, battery energy; code channels; transmission power. The radio assets ought to be overseen in a proficient way to expend income, quality of service adequacy and proficiency of wireless systems. Resource management helps in decreasing the handoff rate and maintains the good QoS during and after the handoff. A percentage of the asset administration related handoffs incorporate affirmation control, data transmission reservation, and power control. [6].

i) In affirmation control, new calls and progressing calls can be dealt with in an unexpected way. It serves to keep the framework from being over-burden. For new calls lining can be consider and handoff solicitation may be organized. The data transfer capacity in a wireless system may be the most valuable and vital asset.

ii) At the point when a data transmission reservation is carried out or when a channel is accessible, a handoff appeal can be completed. [7], [8].

iii) Power control is an essential component in all versatile frameworks in light of a vital part in range and asset portion and also the battery life and security reasons. Power control plans can be utilized to attain to the obliged CIR level (Carrier-Interference Ratio). They attempt to diminish the general CIR in the framework by measuring the received power and expanding or diminishing the transmitted power keeping in mind the end goal to boost the base CIR in a given channel designation of the framework. [9].

\section{VERTICAL HANDOFF DECISION PROBLEM}

Each vertical handoff decision procedure comprises of two stages: Identifying the handoff decision criteria and picking the decision strategy to be executed. Handoff decision criteria comprise of checking the system conditions which can give an indicant of the need of handoff. Handoff decision criteria are utilized to pick the best system. Handoff decision approach utilizes decision criteria to pick the best system by thinking seriously about the execution of the handoff decision [10]

Handoff decision approach essentially worries about the outcomes of the handoff decision, for example, frequency of handoff, latency affected by handoff, packet loss during handoff. A handoff decision arrangement can be outlined focused around different arrangements/algorithms, for example, cost function based algorithms, pattern recognition algorithms, fuzzy and neural systems based algorithm, context aware algorithms, threshold based algorithms, position aware algorithms, and multi attribute algorithms. Despite the fact that, accessibility of various decision criteria and thought of user preference increase the complexity of handoff algorithm. To design an efficient and optimum Handoff decision algorithm is the aim of the research.

\section{VHD CRITERIA}

i) Received signal strength (RSS): It is the most generally utilized paradigm on the grounds that it is not difficult to scale and is specifically identified with the service quality. The RSS is directly related to the distance between the mobile node and its point of attachment. RSS is used as a primary decision criteria in most of the existing handoff decision algorithms. ii) System association time: It is the time span that a mobile node stays connected with a current connection. Deciding the system association time is critical for cutting the privilege minute to initiator a handover with the goal that the service quality could be kept up at a pleasant level. Deciding the system association time is additionally vital for diminishing the quantity of superfluous handovers, as giving over to a target system with conceivably short association time ought to be disheartened. The system association time is related to RSS which is influenced by the network coverage area [12]. Both the separation from the mobile node to its current point of attachment and the speed of the mobile node influence the RSS. The variety of the RSS then decides the period for that the mobile terminal stays associated with a specific network. System association time is particularly important for VHD algorithms on the grounds that heterogeneous systems typically have diverse sizes of network [13].

iii) Available bandwidth: It is a measure of the average number of bits transmitted over a channel. More is the bandwidth, more data information can be transmitted on a channel. It also indicates the traffic load carrying capacity of the network.

iv) Power utilization: Power utilization is an important issue now a day. If a mobile node's battery is low, then it would be desirable to switch to network, which would have low power requirements [14].

v) Money related expense: For distinctive systems, there would be diverse charging strategies, accordingly, in a few circumstances the expense of a system administration ought to be considered over in settling on handover decisions

vi) Security: A system with a higher level of security is always preferred over another may be picked over another which would give a lower level of information security.

vii) User preferences: A client's personal inclination towards an access network might lead to the choice of one kind of network over the other kind.

\section{PERFORMANCE EVAluation METRICS FOR VHD ALGORITHMS}

VHD algorithms can be quantitatively compared under different utilization situations by measuring the minimum and maximum handover delays, number of handover failure probability, and overall throughput of a session during a mobility pattern. These metrics are further explained as below:

i) Handover delay: It refers to the time taken by a handoff algorithm from its initiation to completion. Handoff delay is more for complex VHD algorithms [4].

ii) Number of handovers: Handoff algorithm must minimize the quantity of handovers, as frequent handovers would result in wastage of system assets. A handover is useless, if a switching to the old base station is required within a certain time span [12], and such handovers ought to be minimized.

iii) Handover failure probability: Handover failure is identified with the channel accessibility of the target system [15]. A handover failure happens when the target network does not have sufficient assets to complete the initiated handoff and causes the termination of call.

iv) Throughput: Handover to a system with higher throughput is normally attractive because it is closely related 
the amount of information transmitted on a communication link [15].

\section{VERTICAL HANDOVER DECISION ALGORITHMS}

In this, we divide VHD algorithms into four groups focused around the handover decision criteria utilized and the techniques used to route these.

Some of the algorithms use more than one VHD criteria, and in such cases, we consider the main criterion they use for classification.

\subsection{RSS based VHD algorithms:}

In this type of algorithm, RSS is the primary handoff decision criteria. These algorithms use the RSS of the current network and the candidate network [15]. RSS based handover decision techniques are characterized into the following six subcategories: relative RSS, relative RSS with hysteresis, and relative RSS with an edge and relative RSS with hysteresis and limit, and forecast strategies [4]. For VHD, relative RSS is not sufficient, since RSS from diverse networks cannot be compared directly due to the difference of the innovations included, Furthermore, other system parameters, such as, data transmission rate, packet delay, bandwidth are typically joined with RSS in the VHD procedure.

RSS based VHD algorithms are simplest in nature as less overhead is required for measuring RSS.

\subsubsection{An adaptive lifetime based handover heuristic}

Zahran, A. H., Liang, B., \& Saleh, A., [16] proposed a calculation for handovers between $3 \mathrm{G}$ systems and WLANs by consolidating the RSS estimations either with an expected lifetime metric or the available bandwidth of the WLAN candidate. We depict their technique through the accompanying situations.

In the first case, Handoff from WLAN to $3 \mathrm{G}$ occurs only if RSS of WLAN falls below a predefined threshold and the dwell time of the mobile node is less than handoff delay. In a second case the handoff from $3 \mathrm{G}$ to WLAN is activated only if the RSS \& bandwidth of WLAN is larger than a predefined threshold. There are various benefits of Zahran, A. H., Liang, B., \& Saleh, A., [16] calculation. Firstly, by utilizing the lifetime metric, it reduces the unnecessary handoff. Secondly, it increases the stay time with WLAN network.

\subsubsection{An RSS threshold based dynamic heuristic}

Mohanty, S., \& Akyildiz, I. F., [17] proposed a handover decision algorithm between WLAN and $3 \mathrm{G}$ network based on RSS and dynamic RSS threshold. This algorithm reduces the probability of false handover. However, in this calculation, the handover failure probability from $3 \mathrm{G}$ system to a WLAN cell is thought to be zero since the $3 \mathrm{G}$ system scope is thought to be accessible constantly, and therefore as indicated by the algorithm, a handover to a WLAN is constantly attractive at whatever point the mobile node enters the WLAN coverage.

\subsubsection{A traveling distance prediction based heuristic}

Yan, X., Şekercioğlu, Y. A., \& Narayanan, S., [18] created a VHD calculation that thinks seriously about the time the mobile terminal stays inside a WLAN cell. A handover to a WLAN is activated if the WLAN coverage is available and the dwell time in the WLAN cell is larger than the threshold time. The principle point of interest of this algorithm depends on examining and averaging RSS point, which presents an expanded handover delay and reduction of handover failure and unnecessary handovers.

\subsection{Bandwidth based VHD Algorithms:}

In this group, available bandwidth is the principle criteria for handoff decision algorithm [19]. In a few algorithms, both bandwidth and RSS data are utilized as a part of the decision procedure [15]

\subsubsection{A QoS based heuristic}

Lee, C. W., Chen, L. M., Chen, M. C., \& Sun, Y. S, [20] Proposed an algorithm based on the available bandwidth and type of application in-between WLAN to Wireless Wide Area Network (WWAN). Handoff to WLAN occurs, if the RSS falls below a threshold RSS. The calculation additionally takes the condition of the mobile terminal into assumption. If the mobile terminal is in the idle state, a handover to the favored access system is performed; overall the handover choice is based upon the type of application. For delay sensitive applications, a handover happens just if the current serving WLAN is not ready to give enough bandwidth to the application while the WWAN is able to provide the necessary bandwidth. For delay sensitive applications, a handover happens if the WWAN gives a higher bandwidth than the WLAN.

\subsubsection{A signal to interference and noise ratio (SINR) based heuristic}

Yang, K., Gondal, I., Qiu, B., \& Dooley, L. S., [21] proposed a decision algorithm based on based on Signal to Interference Noise Ratio (SINR) in between WLANs and a Wideband Code Division Multiple Access (WCDMA) system. SINR based handovers can provide higher throughput than RSS based handovers and make a balance load between WLAN and WCDMA. But such a calculation might likewise present excessive handovers with the variation of the SINR bringing on the hub to hand over here and there and then here again between two systems, usually referred to as a ping-pong effect.

\subsubsection{A wrong decision probability (WDP) prediction based heuristic}

Chi, C., Cai, X., Hao, R., \& Liu, F., [8] Proposed a VHD algorithm based on the wrong decision probability (WDP). The WDP is computed by consolidating the likelihood of unnecessary and missing handovers. except that there are two networks up to the expectations $i$ and $j$ with covering scope, and bi and bj are their available bandwidth. An unnecessary handover happens when the mobile node moves to a new network, and it has not sufficient resources to maintain the call. Whereas, in case of missing handover, the current network has not sufficient resources to maintain the call and still the mobile node chooses to stay connected with the current system. The authors demonstrate that this calculation has the capacity to decrease the WDP and offset the load movement; then again, RSS is not considered.

\subsection{Cost function based VHD algorithms}

In this type of algorithm, a cost function is calculated for each candidate network [22] [Guo, Q., Zhu, J., \& Xu, X.], [23] [McNair, J., \& Zhu, F. ]. Different weights are assigned to distinctive input metrics depending upon the system 
conditions and user preferences.The cost function based algorithms combine metrics in a cost function.

\subsubsection{A Multiservice based heuristic}

Zhu, F., \& McNair, J., [24] VHD calculation depends on an expense capacity, which figures the "cost" of candidate networks up to expectations. The calculation organizes all the dynamic applications, and after that the cost of all candidate networks is calculated. The total cost is the sum of input metric, such as bandwidth, power consumption, usage cost and delay. The administration has given over to the network with the minimum cost. In this algorithm they have reduced handover delay \& unnecessary handoffs.

\subsubsection{A cost function based heuristic with normalization and weights distribution}

Like Zhu, F., \& McNair, J., [24] system, Hasswa et al. proposed a cost function based handover decision algorithm in which the normalization and weights distribution techniques are given. High framework throughput and client's fulfillment can be accomplished by using Hasswa's heuristic, however, a portion of the parameters, for example, security and interference levels are hard to measure, and the authors have yet to give data on the most proficient method to quantify these parameters.

\subsubsection{A weighted function based heuristic}

Tawil, R., Pujolle, G., \& Salazar, O., [6] proposed an algorithm, in which computations are made for visited network rather than the mobile node. The assets of the mobile terminal can be saved so that the framework has the ability to attain short handover decision delay, low handover blocking rate and high throughput. However, the system obliges additional collaboration between the mobile node and the point of attachment of visited network, which may cause extra inertness and unreasonable load to the system when there are an expansive number of portable terminals.

\subsection{Combination algorithms}

These VHD algorithms are more complex as compared to other algorithms as they utilize a large number of input parameters. Because of high complexity, researchers apply artificial intelligence algorithm for continuous, real time application [25] By utilizing continuous and real time learning methods, the frameworks can monitor their performance and adjust their own particular structure to make effective handover decision algorithms.

Combinational algorithms are based on fuzzy logic or artificial neural networks, and combine different parameters in the handover choice, such as, the ones used in the cost function algorithm:

\subsubsection{A multilayer feed forward artificial neural network based heuristic}

Nasser, N., Guizani, S., \& Al-Masri, E., [26] proposed a

decision algorithm in which mobile node gathers the information about the available network and send it to a vertical handover manager through a current connection. The vertical handover manager comprises of three primary parts: network handling manager, feature collector and ANN training/selector as shown in Figure 3. The ANN is utilized to focus the best handover target remote system accessible to the mobile, based on the client's inclination.

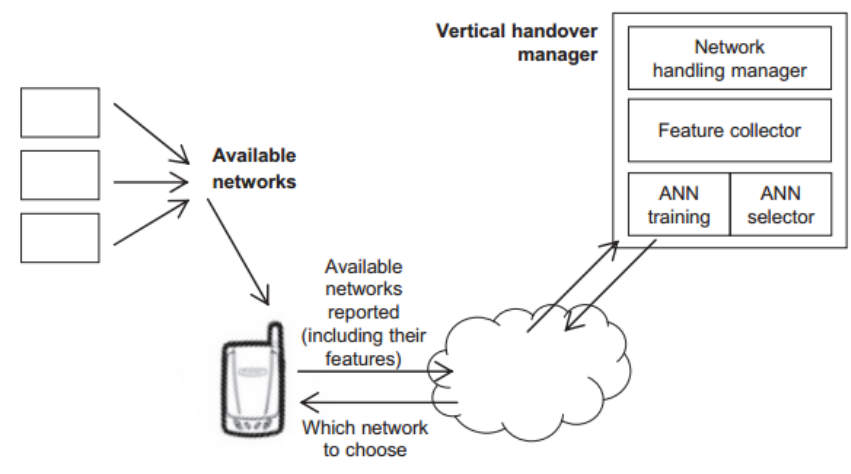

Fig. 3: Architecture of Nasser et al.'s system

It comprises of an information layer, a hidden layer and an output layer. The information layer provides the input parameters of the target network. The hidden layer provides the variable number of activation functions and the output layer creates the system ID of the target network. They select the best network from the available network efficiently. But, their algorithm suffers from a long delay during a training process.

\subsubsection{A method that uses two neural networks}

Pahlavan, K., Krishnamurthy, P., Hatami, A., Ylianttila, M., Makela, J., Pichna, R., \& Vallstron, J. , [25] Proposed two neural systems based decision algorithm. In this handovers, an ANN is utilized for handovers from the WLAN to the General Packet Radio Service (GPRS). The mobile node measures the RSS and the samples of RSS are given to the input of ANN. The output of ANN is binary signal. The binary one output indicates a handoff to the GPRSS and the zero output indicates to stay connected with the present network. Training ANN is carried out by taking various RSS samples from the access point and, utilizing a pattern recognition strategy. This algorithm selects the most suitable system, while minimizing the handover delay and ping-pong effect and the quantity of handovers.

\subsubsection{A fuzzy logic based heuristic}

Xia et al. proposed a decision algorithm for handover between WLANs and Universal Mobile Telecommunications Systems (UMTS). In this, three inputs, current RSS, predicted RSS and bandwidth, are fuzzified and standardized to produce performance evaluation values (PEV), and the handoff decision is based on comparison of RSS values. They have improved the performance by reducing the ping- pong effect. However, when the PEVs are computed, fixed weights are assigned to the three inputs. This is not reasonable on the grounds that the network condition and client prerequisites fluctuate in distinctive circumstances. Likewise, more execution assessment criteria, for example, handover delay and network overloading need to be addressed.

\section{COMPARATIVE ANALYSIS}

So far we have talked about twelve VHD algorithms and arranged them into four groups focused around the criteria they use for settling on handover decisions. In RSS based VHD algorithms, only RSS is used as primary decision criteria. When RSS is combined with bandwidth, the algorithm is called as bandwidth based algorithm. While the RSS consolidated with the bandwidth is generally used in bandwidth based VHD algorithms. For handover target decision criteria, the candidate network with the steadiest RSS 
and highest bandwidth is chosen as the preferred network in RSS and bandwidth based VHD algorithms, respectively. Also, high delays occur in RSS based algorithms. Finally, reliability fluctuates among the algorithms. Variation in RSS declines the reliability of RSS based VHD algorithms, and the trouble in measuring available bandwidth decreases the reliability of bandwidth based VHD algorithms.

In Cost function based or combination algorithms, different system parameters such as usage cost, power consumption, bandwidth requirement, security and delay are used [27], [28] [Cortes-Rodriguez, F., Munoz-Rodriguez, D., \& Soto, R.] [Ghaderi, M., \& Boutaba, R.].

Cost function based VHD algorithms has a tendency to be more unpredictable as they have to gather and standardize different system parameters, and combination algorithms are the most difficult ones as a result of their pre-training requirements. In Cost function based algorithms, a few parameters, for example, security level are hard to measure, and they degrade their reliability.

In Combination algorithms, since the frameworks are prepared in advance, they can be considered as the most solid among the four groups [20] [Lee, C. W., Chen, L. M., Chen, M. C., \& Sun, Y. S.]. On the other hand, combination based algorithms endeavor to pick the target system with the highest overall performance [11] [Calvagna, A., \& Di Modica, G.].

In Table-1, we give a quantitative comparison based on the performance metrics focused around four execution parameters: delay, number of handovers, handover failure probability and throughput. Based on the literature survey, proposed as a part of [17] [Mohanty, S., \& Akyildiz, I. F.], while the authors in [4] [Stevens-Navarro, E., \& Wong, V. W.] contend that their bandwidth and Cost function based algorithms have the ability to keep up shorter handover delays. In the instance of number of handovers, the utilization of algorithms in [15] [Song, Q., \& Jamalipour, A.] lead to diminished number of handovers, the algorithm in [23] [McNair, J., \& Zhu, F.] introduces excessive handovers in view of the variety of SINR, the algorithm in [22] [Guo, Q., Zhu, J., \& Xu, X.] has the capacity to keep the unnecessary handover likelihood at a low level, and algorithms in [25] [Pahlavan, K., Krishnamurthy, P., Hatami, A., Ylianttila, M., Makela, J., Pichna, R., \& Vallstron, J.] reduces the number of handovers by eliminating the Ping-Pong effect. Handover failure probability can simply be held under the desirable value for algorithms in [12], [8] [Wang, H. J., Katz, R. H., \& Giese, J.] [Chi, C., Cai, X., Hao, R., \& Liu, F.], though high handover failure probability is observed for the algorithm in [7], [29] [Chen, W. T., Liu, J. C., \& Huang, H. K.] [NguyenVuong, Q. T., Agoulmine, N., \& Ghamri-Doudane, Y.] without incorporation of RSS. As for throughput, bandwidth and Cost function based algorithms have the ability to accomplish higher throughput than RSS based algorithms.

\section{CONCLUDING REMARKS \& FUTURE RESEARCH DIRECTION}

This paper concludes that RSS and Bandwidth based VHD algorithms are very simple and traditional as they combine RSS with one or two input parameters. These algorithms are easiest to implement. On the other hand, Cost and Combination based algorithms are more complex, and they consider a more extensive range of system parameters as contrasted with others. However, they are basically on the hypothetical examination stage or still too complex for implementation.

\section{REFERENCES}

[1] Nasser, N., Hasswa, A., \& Hassanein, H. (2006). Handoffs in fourth generation heterogeneous networks. Communications Magazine, IEEE, 44(10), 96-103.

[2] Kassar, M., Kervella, B., \& Pujolle, G. (2008). An overview of vertical handover decision strategies in heterogeneous wireless networks. Computer Communications, 31(10), 2607-2620.

[3] Chan, P. M., Sheriff, R. E., Hu, Y. F., Conforto, P., \& Tocci, C. (2001). Mobility management incorporating fuzzy logic for heterogeneous a IP environment. Communications Magazine, IEEE, 39(12), 42-51.

[4] Stevens-Navarro, E., \& Wong, V. W. (2006, May). Comparison between vertical handoff decision algorithms for heterogeneous wireless networks. In Vehicular technology conference, 2006. VTC 2006Spring. IEEE 63rd (Vol. 2, pp. 947-951). IEEE.

[5] Bhuvaneswari, A. (2011). Survey On Handoff Techniques. Journal of Global Research in Computer Science, 2(6), 140-144.

[6] Tawil, R., Pujolle, G., \& Salazar, O. (2008, May). A vertical handoff decision scheme in heterogeneous wireless systems. In Vehicular Technology Conference, 2008. VTC Spring 2008. IEEE (pp. 2626-2630). IEEE.

[7] Chen, W. T., Liu, J. C., \& Huang, H. K. (2004, July). An adaptive scheme for vertical handoff in wireless overlay networks. In Parallel and Distributed Systems, 2004. ICPADS 2004. Proceedings. Tenth International Conference on (pp. 541-548). IEEE.

[8] Chi, C., Cai, X., Hao, R., \& Liu, F. (2007, November). Modeling and analysis of handover algorithms. In Global Telecommunications $\quad 2007$. GLOBECOM'07. IEEE (pp. 4473-4477). IEEE.

[9] Vasu, K., Maheshwari, S., Mahapatra, S., \& Kumar, C. S. (2011, January). QoS aware fuzzy rule based vertical handoff decision algorithm for wireless heterogeneous networks. In Communications (NCC), 2011 National Conference on (pp. 1-5). IEEE.

[10] Balasubramaniam, S., \& Indulska, J. (2004). Vertical handover supporting pervasive computing in future wireless networks. Computer Communications, 27(8), 708-719.

[11] Calvagna, A., \& Di Modica, G. (2004, October). A usercentric analysis of vertical handovers. In Proceedings of the 2nd ACM international workshop on Wireless mobile applications and services on WLAN hotspots (pp. 137146). ACM

[12] Wang, H. J., Katz, R. H., \& Giese, J. (1999, February). Policy-enabled handoffs across heterogeneous wireless networks. In Mobile Computing Systems and Applications, 1999. Proceedings. WMCSA'99. Second IEEE Workshop on (pp. 51-60). IEEE.

[13] Ormond, O., Murphy, J., \& Muntean, G. M. (2006, June). Utility-based intelligent network selection in beyond 3G systems. In Communications, 2006. ICC'06. 
IEEE International Conference on (Vol. 4, pp. 18311836). IEEE.

[14] Keeney, R. L., \& Raiffa, H. (1993). Decisions with multiple objectives: preferences and value trade-offs. Cambridge university press.

[15] Song, Q., \& Jamalipour, A. (2005, May). A network selection mechanism for next generation networks. In Communications, 2005. ICC 2005. 2005 IEEE International Conference on (Vol. 2, pp. 1418-1422). IEEE.

[16] Zahran, A. H., Liang, B., \& Saleh, A. (2006). Signal threshold adaptation for vertical handoff in heterogeneous wireless networks. Mobile Networks and Applications, 11(4), 625-640.

[17] Mohanty, S., \& Akyildiz, I. F. (2006). A cross-layer (layer 2+3) handoff management protocol for nextgeneration wireless systems. Mobile Computing, IEEE Transactions on, 5(10), 1347-1360.

[18] Yan, X., Şekercioğlu, Y. A., \& Narayanan, S. (2010). A survey of vertical handover decision algorithms in Fourth Generation heterogeneous wireless networks. Computer Networks, 54(11), 1848-1863.

[19] Guo, C., Guo, Z., Zhang, Q., \& Zhu, W. (2004). A seamless and proactive end-to-end mobility solution for roaming across heterogeneous wireless networks. Selected Areas in Communications, IEEE Journal on, 22(5), 834-848.

[20] Lee, C. W., Chen, L. M., Chen, M. C., \& Sun, Y. S. (2005). A framework of handoffs in wireless overlay networks based on mobile IPv6. Selected Areas in Communications, IEEE Journal on, 23(11), 2118-2128.

[21] Yang, K., Gondal, I., Qiu, B., \& Dooley, L. S. (2007, November). Combined SINR based vertical handoff algorithm for next generation heterogeneous wireless networks. In Global Telecommunications Conference, 2007. GLOBECOM'07. IEEE (pp. 4483-4487). IEEE.

[22] Guo, Q., Zhu, J., \& Xu, X. (2005, May). An adaptive multi-criteria vertical handoff decision algorithm for radio heterogeneous network. In Communications, 2005. ICC 2005. 2005 IEEE International Conference on (Vol. 4, pp. 2769-2773). IEEE.

[23] McNair, J., \& Zhu, F. (2004). Vertical handoffs in fourth-generation multinetwork environments. Wireless Communications, IEEE, 11(3), 8-15. IEEE VTS 50th (Vol. 2, pp. 775-779). IEEE.
[24] Zhu, F., \& McNair, J. (2004, March). Optimizations for vertical handoff decision algorithms. In Wireless Communications and Networking Conference, 2004. WCNC. 2004 IEEE (Vol. 2, pp. 867-872). IEEE.

[25] Pahlavan, K., Krishnamurthy, P., Hatami, A., Ylianttila, M., Makela, J., Pichna, R., \& Vallstron, J. (2000). Handoff in hybrid mobile data networks. Personal Communications, IEEE, 7(2), 34-47.

[26] Nasser, N., Guizani, S., \& Al-Masri, E. (2007, June). Middleware vertical handoff manager: A neural networkbased solution. In Communications, 2007. ICC'07. IEEE International Conference on (pp. 5671-5676). IEEE.

[27] Cortes-Rodriguez, F., Munoz-Rodriguez, D., \& Soto, R. (1999). Position location assisted multi-valued logic handoff algorithm. In Vehicular Technology Conference, 1999. VTC 1999-Fall.

[28] Ghaderi, M., \& Boutaba, R. (2006). Call admission control in mobile cellular networks: a comprehensive survey. Wireless communications and mobile computing, 6(1), 69-93.

[29] Nguyen-Vuong, Q. T., Agoulmine, N., \& GhamriDoudane, Y. (2007). Terminal-controlled mobility management in heterogeneous wireless networks. Communications Magazine, IEEE, 45(4), 122-129.

\section{AUTHORS' PROFILES}

Jyoti Madaan was born in 1983 at Faridabad, Haryana, INDIA. Received her Master's Degree in Electronics \& Communication Engineering in the years 2009. She is working as Assistant Professor, Department of E\&C Engineering, at Manav Rachna International University, Faridabad, India, since 2010. Currently, she is doing her research in the area of Wireless Networks under the guidance of Dr. Indu Kashyap.

Dr. Indu Kashyap completed her Doctorate in Computer Science in the year 2012. She has around Eight years of Academic experience in the field of Computer Science. Currently She is working as Associate Professor in the Department of Computer Science and Engineering at Manav Rachna International University, Faridabad, India. Her research interest includes Wireless networking, Mobile computing, Computer Communication and Networks. She has published several papers in National, International Journals and Conferences related to Computer 
Table: 1 Comparative Analysis of Vertical Handoff Decision Algorithm Strategies

\begin{tabular}{|c|c|c|c|c|c|}
\hline Groups & & Delay & Number of handovers & $\begin{array}{l}\text { Handover failure } \\
\text { probability }\end{array}$ & Throughput \\
\hline \multirow[t]{3}{*}{ RSS based } & $\begin{array}{l}\text { Zahran et al.'s } \\
\text { algorithm }\end{array}$ & $\begin{array}{l}\text { Relatively high packet } \\
\text { delay probability }\end{array}$ & $\begin{array}{l}\text { Reduces up to } 85 \% \text { as } \\
\text { compared to } \\
\text { traditional hysteresis VHD }\end{array}$ & Not provided & $\begin{array}{l}\text { Decreases as the velocity } \\
\text { increases; }\end{array}$ \\
\hline & $\begin{array}{l}\text { Mohanty and } \\
\text { Akyildiz's } \\
\text { algorithm }\end{array}$ & Not provided & Not provided & $\begin{array}{l}\text { Controlled to desirable } \\
\text { value }(2 \%)\end{array}$ & Not provided \\
\hline & $\begin{array}{l}\text { Yan et al.'s } \\
\text { algorithm }\end{array}$ & $\begin{array}{l}\text { Extra RSS sampling } \\
\text { delay }\end{array}$ & $\begin{array}{l}\text { Decreases as the velocity } \\
\text { increases; }\end{array}$ & $\begin{array}{l}\text { Controlled to desirable } \\
\text { value }(0.02\end{array}$ & Not provided \\
\hline \multirow[t]{3}{*}{ Bandwidth based } & $\begin{array}{l}\text { Lee et al.'s } \\
\text { algorithm }\end{array}$ & $\begin{array}{l}\text { Short handover delay } \\
\text { (average } 455 \mathrm{~ms} \text { ) }\end{array}$ & Not provided & Not provided & $\begin{array}{l}\text { Higher throughput (up to } \\
400\end{array}$ \\
\hline & $\begin{array}{l}\text { Yang et al.'s } \\
\text { algorithm }\end{array}$ & Not provided & $\begin{array}{l}\text { Excessive handovers due to } \\
\text { variation of SINR }\end{array}$ & Not provided & $\begin{array}{l}\text { Higher overall } \\
\text { throughput (up to } 40 \% \text { ) }\end{array}$ \\
\hline & $\begin{array}{l}\text { Chi et al.'s } \\
\text { algorithm }\end{array}$ & Not provided & $\begin{array}{l}\text { Small unnecessary handover } \\
\text { probability }\end{array}$ & $\begin{array}{l}\text { High handover failure } \\
\text { probability }\end{array}$ & $\begin{array}{l}\text { High throughput } \\
\text { achieved by balancing } \\
\text { the traffic load }\end{array}$ \\
\hline \multirow[t]{3}{*}{ Cost function based } & $\begin{array}{l}\text { Zhu and McNair's } \\
\text { algorithm }\end{array}$ & Not provided & Not provided & Not provided & High overall throughput \\
\hline & $\begin{array}{l}\text { Hasswa et al.’s } \\
\text { algorithm }\end{array}$ & Not provided & Not provided & Not provided & Increases by up to $57.9 \%$ \\
\hline & $\begin{array}{l}\text { Tawil et al.'s } \\
\text { algorithm }\end{array}$ & $\begin{array}{l}\text { Around } 50 \% \text { shorter } \\
\text { handover delay as } \\
\text { compare to centralized } \\
\text { VHD }\end{array}$ & Not provided & $\begin{array}{l}\text { Low handover failure } \\
\text { rate }\end{array}$ & $\begin{array}{l}\text { Around } 17 \% \text { higher } \\
\text { throughput as compare } \\
\text { to centralize VHD }\end{array}$ \\
\hline \multirow[t]{3}{*}{$\begin{array}{l}\text { Combination } \\
\text { algorithms }\end{array}$} & $\begin{array}{l}\text { Nasser et al.'s } \\
\text { algorithm }\end{array}$ & Long handover delay & Not provided & Not provided & Not provided \\
\hline & $\begin{array}{l}\text { Pahlavan et al.'s } \\
\text { algorithm }\end{array}$ & Long delay & $\begin{array}{l}\text { Reduced number of } \\
\text { handovers }\end{array}$ & Not provided & Not provided \\
\hline & $\begin{array}{l}\text { Xia et al.’s } \\
\text { algorithm }\end{array}$ & Not provided & $\begin{array}{l}\text { Reduced number of } \\
\text { handovers }\end{array}$ & Not provided & Not provided \\
\hline
\end{tabular}

